\title{
CHARACTERIZATION OF ACID SOLUBLE COLLAGEN FROM THE SKIN OF SNAKESKIN GOURAMI (TRICHOGASTER PECTORALIS)
}

\author{
Piyaporn Sukkon ${ }^{1}$, Ali Muhammed Moula Ali ${ }^{1}$, Sitthipong Nalinanon ${ }^{1 凶}$, Hideki Kishimura ${ }^{2}$, \\ Sirima Takeungwongtrakul ${ }^{3}$ \\ ${ }^{1}$ Faculty of Food Industry, King Mongkut's Institute of Technology Ladkrabang, \\ Ladkrabang, Bangkok, 10520, Thailand \\ ${ }^{2}$ Laboratory of Marine Chemical Resource Development, Faculty of Fisheries Sciences, Hokkaido University, \\ Hakodate, Hokkaido, 041-8611, Japan \\ ${ }^{3}$ Department of Agricultural Education, Faculty of Industrial Education and Technology, King Mongkut's \\ Institute of Technology Ladkrabang, Ladkrabang, Bangkok, 10520, Thailand \\ sitthipong.na@kmitl.ac.th \\ https://doi.org/10.34302/crpjfst/2020.12.2.8
}

Article history:

Received:

23 February 2020

Accepted:

22 May 2020

Keywords:

Characterization;

Collagen;

Trichogaster pectoralis;

Skin;

Snakeskin gourami.

\section{ABSTRACT}

The present study was aimed to isolate and characterized acid soluble collagen (ASC) from the skin of snakeskin gourami (Trichogaster pectoralis). ASC from gourami skin had a yield of $9.43 \%$ and $34.65 \%$, based on wet and dry weight basis, respectively. The purity of ASC was superior with a distinct absorption peak at wavelength (WL) of $230.7 \mathrm{~nm}$. Based on the electrophoretic pattern, gourami skin ASC was classified as type I collagen, as it comprised $\alpha 1$ and $\alpha 2$ as major components and higher molecular weight (MW) components $\gamma, \beta$ were distinctly observed. ASC exhibited high $\mathrm{T}_{\max }$ value of $33.43^{\circ} \mathrm{C}$, which could correspond to its imino acids content of 188 residues/1000 residues. Fourier transform infrared (FTIR) spectrum and circular dichroism (CD) revealed that ASC extracted from gourami skin had greater structural integrity in its triple-helical form. Solubility of ASC was high at the $\mathrm{pH}$ range of 2-4 in which zeta potential exhibited highly positive charge. The highest solubility of ASC in the presence of $\mathrm{NaCl}$ was observed at $2 \%(\mathrm{w} / \mathrm{v})$. Therefore, with all the characteristic features, ASC from snakeskin gourami skin can be a valueadded product in the fish processing industry.

\section{Introduction}

Fish processing generates up to $70 \%$ of organic by-products, depending on species. Increasing interest has been paid from the fish processors to effectively utilize these byproducts to produce value added products, especially collagen and gelatin (Kittiphattanabawon et al., 2019). Collagens with different properties have been extracted from bone, skin and scales of common carp (Cyprinus carpio) (Duan et al., 2009), skin of bigeye snapper (Lutjanus lutjanus) (Benjakul et al., 2010), scales of golden carp (Probarbus jullieni) (Ali et al., 2017) and the swim bladder of seabass (Paralabrax spp.) (Sinthusamran et al., 2013). Collagen is a major structural protein present in connective tissues (skin and bone) of animal. Collagen has wide range of applications ranging from cosmetic, biomedical, pharmaceutical, leather to film industries (Nalinanon et al., 2011; Ogawa et $a l ., 2003)$. Fish skin being rich in collagenous protein, can serve as an excellent source for collagen production alternative to mammalian counter parts, which is mostly associated with several disadvantages such outbreak of mad cow disease and religions constraint, mainly 
Islam and Judaism (Ali et al., 2018; Nalinanon et al., 2011).

Snakeskin gourami (Trichogaster pectoralis) is one of the common fish species of Thailand, habitat in shallow, sluggish or standing water with a lot of aquatic vegetation and in rice paddies and swamps. Due to its taste, it is highly valued for food and has been exported to other countries (Froese, 2014), and is one of the five most important aquacultured freshwater species in Thailand (Pongsri, 2005). Its flesh is appreciated for its good eating quality, and is eaten in the form of fried, grilled, fish soup or dried from (Froese, 2014). Due to its wide availability and acceptability, generation of its processing by-product, especially skin is in the significant amounts. This skin can be effectively utilized for the production of value-added products particularly collagen or gelatin which can be of highly significant as well as benefit the fish processers. Therefore, the objective of this study was to extract and characterize the acid soluble collagen (ASC) from the skin of snakeskin gourami in order to evaluate its possible use as an added value by-product for the fish processing industry.

\section{Materials and methods}

\subsection{Chemicals}

All chemicals were of analytical grade. Bovine hemoglobin, $\beta$-mercaptoethanol $(\beta$ $\mathrm{ME}$ ), standard collagen type I were purchased from Sigma Chemical Co. (St Louis, MO, USA). Trichloroacetic acid, disodium hydrogen phosphate, sodium citrate, acetic acid, FolinCiocalteu's phenol reagent and tris(hydroxylmethyl) aminomethane were obtained from Merck (Darmstadt, Germany). Coomassie Blue R-250 and $N, N, N^{\prime}, N^{\prime}-$ tetramethylethylenediamine (TEMED) were procured from Bio-Rad Laboratories (Hercules, CA, USA). Sodium dodecyl sulfate (SDS) and bovine serum albumin were obtained from Fluka (Buchs, Switzerland).

\subsection{Preparation of fish skins}

Freshly available snakeskin gourami (Trichogaster pectoralis) was purchased from the local market situated in Samut Prakan province of Thailand. Fish were packed in a polyethylene bags, loaded in ice with a sample:ice ratio of $1: 2(\mathrm{w} / \mathrm{w})$ and transported to the Faculty of Agro-Industry, King Mongkut's Institute of Technology Ladkrabang, Bangkok within $1 \mathrm{~h}$. The skins were manually removed with a filleting knife and washed with cold distilled water. Cleaned skins were cut into small pieces $\left(0.5 \times 0.5 \mathrm{~cm}^{2}\right)$ using scissors. The prepared skins were placed in a polyethylene bag and stored at $-20^{\circ} \mathrm{C}$ until used for collagen extraction.

\subsection{Extraction of acid soluble collagens (ASC)}

Acid soluble collagen (ASC) was extracted following the method of Kittiphattanabawon et al. (2019) with slight modification. All processes were carried out at $4{ }^{\circ} \mathrm{C}$ under continuous stirring condition. Noncollagenous proteins were removed by soaking the prepared skin in $0.1 \mathrm{M} \mathrm{NaOH}$ at a skin/ alkali solution ratio of $1: 15 \quad(\mathrm{w} / \mathrm{v})$. The mixture was continuously stirred for $6 \mathrm{~h}$ and the alkali solution was changed for every $2 \mathrm{~h}$. The treated skins were then washed in cold water to achieve neutral $\mathrm{pH}$. Followed by defatting in $10 \%$ butyl alcohol at a sample:solvent ratio of $1: 10(\mathrm{w} / \mathrm{v})$ for $18 \mathrm{~h}$, the solvent was changed for every $6 \mathrm{~h}$. The defatted skin was then washed with cold water. Collagen was extracted by soaking the pretreated skin in $0.5 \mathrm{M}$ acetic acid at a solid:solvent ratio of $1: 15(\mathrm{w} / \mathrm{v})$ for $48 \mathrm{~h}$. After extraction, the mixture was filtered using two layered cheese cloth and the residue was re-extracted under the same condition. Both, the extracts were combined, and collagen was precipitated by adding $\mathrm{NaCl}$ at a final concentration of $2.6 \mathrm{M}$ in presence of 0.05 $\mathrm{M}$ Tris- $\mathrm{HCl} \quad(\mathrm{pH}$ 7.5). The resultant precipitate was collected by centrifuging at $15,000 \mathrm{~g}$ for $1 \mathrm{~h}$ (Heraeus Primo, Thermo Scientific, Germany) and was dissolved in a minimum volume of 0.5 $M$ acetic acid, 
followed by dialyzing against $0.1 \mathrm{M}$ acetic acid for 2 days. Thereafter, dialyzed against distilled water for 2 days by a changing the solution for every $12 \mathrm{~h}$. The dialysate was freeze dried and was referred to as "ASC".

Hydroxyproline content of ASC was determined according to the method of Nalinanon et al. (2007). The yield of ASC was calculated based on the dry weight of prepared skin using the following equation:

Yield $(\%)=($ Weight of ASC $(\mathrm{g}) /$ Dry weight of prepared skin $(\mathrm{g})) \times 100$

\subsection{Characterization of ASC \\ 2.4.1. UV absorption}

The samples were solubilized in $0.5 \mathrm{M}$ acetic acid to obtain a final concentration of 2 $\mathrm{g} / \mathrm{L}$. UV absorption spectra of collagens were measured using a spectrophotometer (V-730, Jusco Co., Japan). Prior to measurement, the baseline was set with $0.5 \mathrm{M}$ acetic acid. The spectra were obtained by scanning the wavelength in the range of 200-300 nm with a scan speed of $50 \mathrm{~nm} / \mathrm{min}$ at room temperature.

\subsubsection{Sodium dodecylsulfate-polyacerylamide gel electrophoresis (SDS-PAGE)}

SDS-PAGE was performed according to the method of Laemmli (1970). The collagen samples were dissolved in 5\% SDS and heated at $85{ }^{\circ} \mathrm{C}$ for $1 \mathrm{~h}$. The mixtures were centrifuged at $4000 \times \mathrm{g}$ for $5 \mathrm{~min}$ to remove undissolved debris. The solubilized samples were mixed at a $1: 1(\mathrm{v} / \mathrm{v})$ ratio with the sample buffer $(0.5 \mathrm{M}$ Tris- $\mathrm{HCl}, \mathrm{pH}$ 6.8, containing 4\% SDS, 20\% glycerol) in the presence or absence of $10 \% \beta$ mercaptoethanol. Samples (15 $\mu$ g protein) were loaded onto a polyacrylamide gel (4\% stacking gel and $7.5 \%$ separating gel) and subjected to electrophoresis at a constant current of $15 \mathrm{~mA}$ per gel, using an electrophoresis apparatus (AE-6440, Atto Co., Tokyo, Japan). After electrophoresis, the gel was stained with $0.25 \%$ Coomassie brilliant blue R-250 in $15 \%(\mathrm{v} / \mathrm{v})$ methanol and $5 \%(\mathrm{v} / \mathrm{v})$ acetic acid then destained with $30 \%(\mathrm{v} / \mathrm{v})$ methanol and $10 \%$ (v/v) acetic acid. Gels were imaged using a scanner (MFC-L2700DW, Brother, UK) and band intensities were quantified with the public domain digital analysis software, ImageJ (ImageJ 1.51t, National Institutes of Health, Bethesda, USA). High molecular weight marker (Sigma Chemical Co., USA) was used to estimate the molecular weight of proteins. Type I collagen from calf skin was used as a standard.

\subsubsection{Amino acid composition}

Collagens were hydrolyzed under reduced pressure in $4.0 \mathrm{M}$ methanesulfonic acid containing $0.2 \%$ (v/v) 3-2(2-aminoethyl) indole at $115^{\circ} \mathrm{C}$ for $24 \mathrm{~h}$. The hydrolyzates were neutralized with $3.5 \mathrm{M} \mathrm{NaOH}$ and diluted with $0.2 \mathrm{M}$ citrate buffer ( $\mathrm{pH} 2.2$ ). An aliquot of 0.4 $\mathrm{mL}$ was applied to an amino acid analyzer (MLC-703; Atto Co., Tokyo, Japan).

\subsubsection{Differential scanning calorimetry (DSC)}

DSC was conducted using a differential scanning colorimeter model DSC 7 (Perkin Elmer, Norwalk, CT, USA). The denaturation temperature $\left(\mathrm{T}_{\max }\right)$ and enthalpy $(\Delta \mathrm{H})$ calibrations were determined using indium. ASC were rehydrated in a $0.05 \mathrm{M}$ acetic acid solution with a sample:solution ratio of 1:40 $(\mathrm{w} / \mathrm{v})$. The mixtures were allowed to stand for 2 days at $4{ }^{\circ} \mathrm{C}$. The sample $(5-10 \mathrm{mg})$ was accurately weighed into aluminium pans and sealed. The sample was scanned at $1{ }^{\circ} \mathrm{C} / \mathrm{min}$ over the range of $20-50{ }^{\circ} \mathrm{C}$ using iced water as the cooling medium. An empty pan was used as the reference. The maximum transition temperature $\left(\mathrm{T}_{\max }\right)$ was estimated from the thermogram. Total denaturation enthalpy $(\Delta \mathrm{H})$ was estimated by measuring the area of DSC thermogram.

\subsubsection{Secondary structure}

Fourier transform infrared (FTIR) spectra of collagen from the skin of snakeskin gourami was obtained using Bruker Model EQUINOX 55 FTIR spectrometer (Bruker, Ettlingen, Germany). Collagens samples were placed onto 
the crystal cell. The spectra were acquired over the range of $4000-800 \mathrm{~cm}^{-1}$ with a resolution of $4 \mathrm{~cm}^{-1}$ for 32 scans against a background spectrum recorded from the clean empty cell at $25^{\circ} \mathrm{C}$. Analysis of spectral data was carried out using the OPUS 3.0 data collection software programme (Bruker, Ettlingen, Germany).

Circular dichroism (CD) spectra of collagen was determined by dissolving the samples in $0.5 \mathrm{M}$ acetic acid to obtain a concentration of $0.5 \mathrm{mg} / \mathrm{mL}$ The spectra of all the solutions were recorded from the wavelength of 300-190 nm (Jasco J-815, Japan Spectroscopic Co., Japan).

\subsubsection{Solubility of $A S C$}

\subsubsection{Effect of $\mathrm{NaCl}$ on collagen solubility}

The samples were dissolved in $0.5 \mathrm{M}$ acetic acid at $4{ }^{\circ} \mathrm{C}$ for $24 \mathrm{~h}$ to produce a final concentration of $6 \mathrm{mg} / \mathrm{mL}$. Next, $5 \mathrm{~mL}$ of prepared solutions were mixed with $5 \mathrm{~mL}$ of $0.5 \mathrm{M}$ acetic acid containing various concentrations of $\mathrm{NaCl}(0 \%, 1 \%, 2 \%, 3 \%, 4 \%$, $5 \%$ and $6 \%(\mathrm{w} / \mathrm{v})$. The mixture was stirred continuously at $4{ }^{\circ} \mathrm{C}$ for $30 \mathrm{~min}$, followed by centrifugation at $20,000 \mathrm{~g}$ at $4{ }^{\circ} \mathrm{C}$ for $30 \mathrm{~min}$. Protein content in the supernatant was measured by the method of Lowry et al. (1951), using bovine serum albumin as a standard. Relative solubility was calculated as above.

\subsubsection{Zeta potential}

ASC were dissolved in $0.5 \mathrm{M}$ acetic acid at a concentration of $0.5 \mathrm{mg} / \mathrm{mL}$. The mixture was stirred at $4{ }^{\circ} \mathrm{C}$ for $12 \mathrm{~h}$. The zeta potential was measured using a zeta potential analyzer (ZetaPALS, Brookhaven Instruments Co., Holtsville, NY, USA). The zeta potential of ASC adjusted to different $\mathrm{pH}$ values with $1.0 \mathrm{M}$ nitric acid or $1.0 \mathrm{M} \mathrm{KOH}$ using an Autotitrator (BI-ZTU, Brookhaven Instruments Co.) was determined. The isoelectric point was estimated from $\mathrm{pH}$ rendering zero zeta potential.

\subsection{Statistical analysis}

Analysis of variance (ANOVA) was performed on the data and differences between means were evaluated using the Duncan's multiple range test. SPSS Statistic Program was used for data analysis.

\section{Results and discussions \\ 3.1. Yield of ASC}

The yield of ASC extracted from the skin of snakeskin gourami was $9.43 \%$ on a wet weight basis and $34.65 \%$ on a dry weight basis, similar results were reported by Jongjareonrak et al. (2005). Kittiphattanabawon et al. (2005) reported that the yield of ASC from the skin of brownstripe red snapper was 9\% (wet weight basis) whereas collagen from skin and bone of bigeye snapper yielded 9.38\%. The hydroxyproline content of the ASC extracted from the skin of snakeskin gourami was $23.2 \pm 1.24 \mathrm{mg} / \mathrm{mL}$ which was about 3 times higher than that of its fresh skin $(7.22 \pm 0.6$ $\mathrm{mg} / \mathrm{mL})$. The skin raw material could not totally solubilize by $0.5 \mathrm{M}$ acetic acid, indicating the present of high molecular crosslink components in the skin matrix. The differences in extraction yield might be attributed to the differences in fish species, tissue structure and composition, biological conditions, and preparative methods (Ali et al., 2018; Jongjareonrak et al., 2005; Kittiphattanabawon et al., 2019; Sinthusamran et al., 2013).

\subsection{UV absorption spectrum}

Maximum UV absorption spectrum of ASC from snakeskin gourami was $230.7 \pm 0.3 \mathrm{~nm}$ (Figure 1), which was similar to those of collagens from the skins of ornate threadfin bream (230 nm) (Nalinanon et al., 2011), channel catfish (232 nm) (Lui et al., 2007) and Rutilus Frisii Kutum (240 nm) (Naderi Gharagheshlagh et al., 2019). Generally, the absorption wavelength of protein is from tyrosine, tryptophan, and phenylalanine in the near UV region of 260-290 $\mathrm{nm}$. Generally, the tyrosine and tryptophan residues are known to absorb UV light at $280 \mathrm{~nm}$ (Ali et al., 2017). 
But the amount of tyrosine in ASC was 3 residues per 1000 residues. In addition, Edwards et al. (1997) found that ASC from Oreochromis niloticus skin showed a maximum absorption at $220 \mathrm{~nm}$, which was related to the $\mathrm{C}=\mathrm{O}$, $-\mathrm{COOH},-\mathrm{CONH}_{2}$ groups in polypeptides chains of collagen.



Figure 1. UV absorption spectrum of ASC from the skin of snakeskin gourami.

\subsection{Protein patterns}

Protein patterns of ASC and skin of snakeskin gourami are shown in Figure 2. The result revealed that both the samples contained $\alpha 1$-chain and $\alpha 2$-chain at a ratio of approximately $2: 1$, suggesting that type I collagen was the major protein component in the skin. It was noted that ASC mainly contained the highest band intensity of $\beta$-chains and $\gamma$-chain,which is consistent with findings reported for type I collagen from the skins of hake and trout (Montero et al., 1990), golden carp (Ali et al., 2018) and bigeye snapper (Kittiphattanabawon et al., 2005). Collagen from the swim bladder of seabass was also reported to be type I collagen (Sinthusamran, et al., 2013). The ratio between $\alpha 1$-chain and $\alpha 2$ chain of snakeskin gourami was 2.37 , which is similar to that from skin of ornate threadfin bream (2.18) (Nalinanon et al., 2011). Band intensity ratios of ASC from snakeskin gourami skin (Figure 2A), Ornate threadfin bream, Deep-sea redfish, Black drum fish and calf skin (Table 1) show high population of cross-linked chains $(\gamma$ and $\beta)$. The results are in accordance with collagen from the skin of Ornate threadfin bream (2.18) and Deep-sea redfish (2.47) reported by Nalinanon et al. (2011) and Wang et al. (2007). ASC from the skin of snakeskin gourami found band intensity ratio of $\beta /(\alpha 1+$ $\alpha 2)$ was 1.18 that was lower than in ASC from the skin of Ornate threadfin bream (1.39), and black drum fish (1.59) (Nalinanon et al., 2011; Ogawa et al., 2003). The different band intensity ratios of $\alpha 1 / \alpha 2, \beta /(\alpha 1+\alpha 2), \gamma /(\alpha 1+$ $\alpha 2)$ and $\mathrm{HMC} /(\alpha 1+\alpha 2)$ were specifically observed in collagen and could identify the proportion of monomer chain and cross-linked chain. 


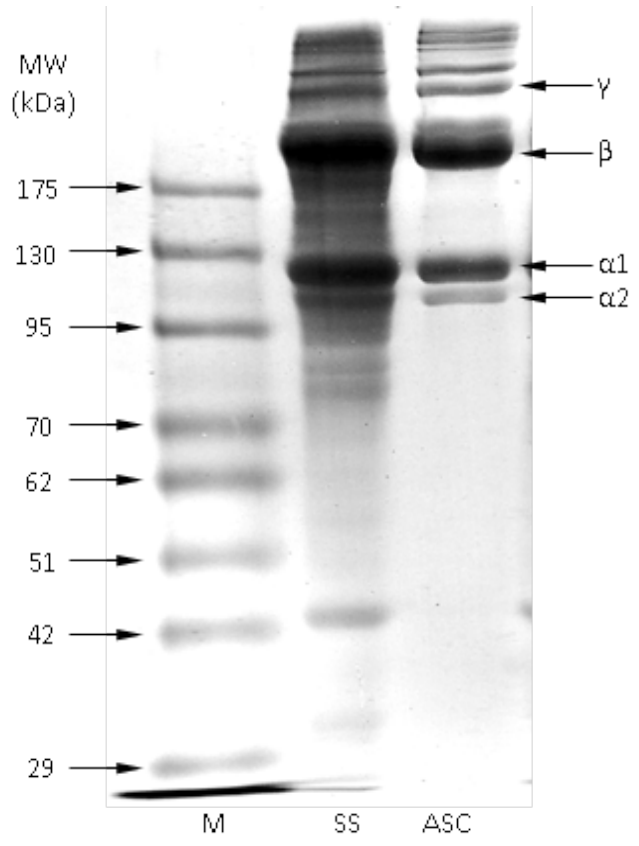

[A]

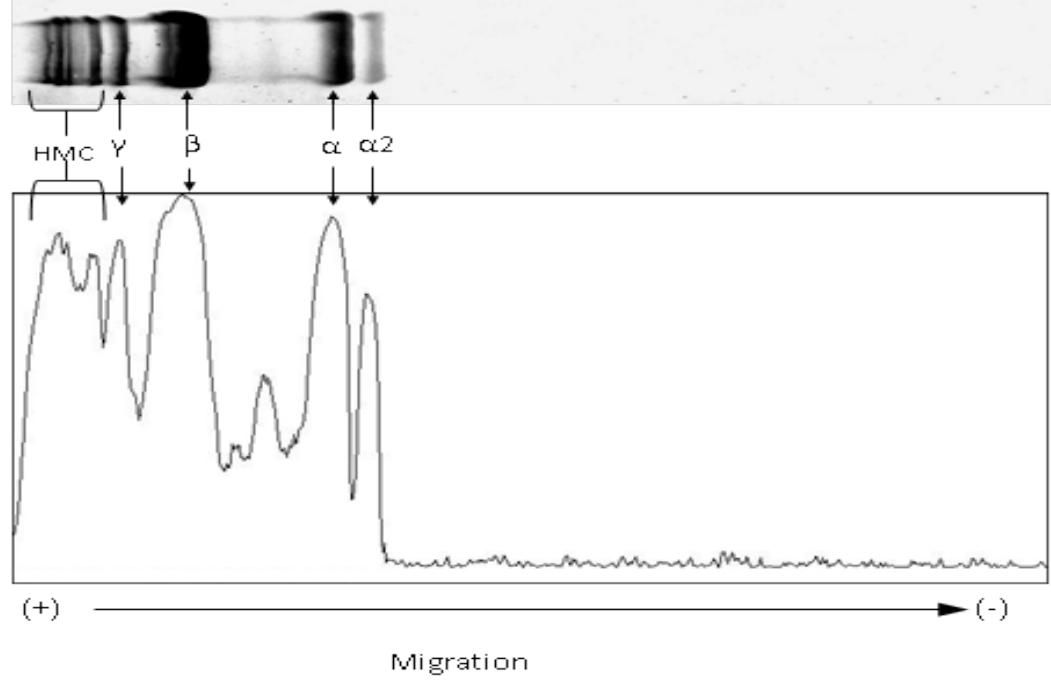

Figure 2. Protein patterns of the skin of snakeskin gourami (SS) and its acid soluble collagen (ASC) counterpart [A] and densitogram of ASC [B]. M denotes high-molecular weight protein markers. HMC is high molecular weight component.

Table 1. Band intensity ratios of collagens from the skin of snakeskin gourami (ASC) in comparison with ornate threadfin bream, deep-sea redfish, black drum, and calf skin.

\begin{tabular}{|l|c|c|c|c|c|}
\hline \multirow{2}{*}{ Components } & \multicolumn{5}{|c|}{ Band intensity ratio } \\
\cline { 2 - 6 } & ASC & $\begin{array}{c}\text { Ornate threadfin } \\
\text { bream }^{(a)}\end{array}$ & $\begin{array}{c}\text { Deep-sea } \\
\text { redfish }^{(b)}\end{array}$ & Black drum $^{(\mathrm{c})}$ & Calf $^{\text {(c) }}$ \\
\hline$\alpha 1 / \alpha 2$ & 2.37 & 2.18 & 2.47 & ND & ND \\
\hline$\beta /(\alpha 1+\alpha 2)$ & 1.18 & 1.39 & 1.52 & 1.59 & 1.26 \\
\hline
\end{tabular}




\begin{tabular}{|l|l|l|l|l|l|}
\hline$\gamma /(\alpha 1+\alpha 2)$ & 0.45 & 0.33 & 1.1 & 1.32 & 0.75 \\
\hline $\mathrm{HMC} /(\alpha 1+\alpha 2)$ & 1.15 & 0.62 & ND & ND & ND \\
\hline
\end{tabular}

$\mathrm{D}=$ Not determined.

Sources :(a) Nalinanon et al. (2011); (b) Wang et al. (2007) and (c) Ogawa et al. (2003).

\subsection{Amino acid composition}

The amino acid composition of ASC was expressed as "residues per 1000 total amino acid residues" (Table 2). Type I collagen and ASC from the skin of snakeskin gourami were rich in glycine, alanine, proline, and hydroxyproline and had low or no residues of cysteine, tyrosine and hydroxylysine (Singh $e t$ al., 2011). Glycine was the most abundant compound with 332 and 313 units of the total amino acids present in type I collagen and ASC, respectively. Generally, glycine in collagen represent almost one third of the total residues and occurs every third residue in collagen except for the first 14 amino acid residues from $\mathrm{N}$-terminus and the first 10 residues from the $\mathrm{C}$-terminus (Foegeding, 1996). Both collagens had proline (130 and 115 residues/1000 residues), alanine (108 and 124 residues/1000 residues) and hydroxyproline (95 and 73 residues/1000 residues). Alanine was the second most abundant amino acid in all collagens. All collagens contained no cysteine and negligible tryptophan. The imino acid (proline and hydroxyproline) content of type I collagen and ASC were 225 and 188 residues/1000 residues, respectively. ASC was relatively higher than those of ASCs from ballon fish skin (179 residues/1000 residues) (Huang et al., 2011), cod skin (179 residues/1000 residues), carp skin (179 residues/1000 residues) (Duan et al., 2009), swim bladders of seabass (128 residues/1000 residues) (Kaewdang et al., 2014) but was slightly lower than cobia skin (203 residues/1000 residues) (Zeng et al., 2012), brownbanded bamboo shark skin (204 residues/1000 residues) (Kittiphattanabawon et al., 2010), striped catfish skin (206 residues/1000 residues) (Singh et al., 2011). The imino acid content was used to determine the thermal stability of collagen and the formation of junction zones via hydrogen boding (Sinthusamran et al., 2013). The pyrrolidine rings of proline and hydroxyproline impose restrictions on the conformation of polypeptide chains and help to strengthen the triple helix (Wang et al., 2007).

Table 2. Amino acid composition of acid soluble collagen (ASC) from the skin of snakeskin gourami and calf skin type I collagen (residues/1000 residues)

\begin{tabular}{|l|c|c|}
\hline Amino acid & Type I collagen & ASC \\
\hline Alanine & 108 & 124 \\
\hline Arginine & 49 & 55 \\
\hline Aspartic acid/asparagine & 45 & 49 \\
\hline Cysteine & 0 & 0 \\
\hline Glutamic acid/glutamine & 73 & 75 \\
\hline Glycine & 332 & 313 \\
\hline Histidine & 5 & 6 \\
\hline Isoleucine & 12 & 12 \\
\hline Leucine & 24 & 27 \\
\hline
\end{tabular}




\begin{tabular}{|l|c|c|}
\hline Lysine & 27 & 28 \\
\hline Hydroxylysine & 7 & 6 \\
\hline Methionine & 6 & 11 \\
\hline Phenylalanine & 12 & 16 \\
\hline Hydroxyproline & 95 & 73 \\
\hline Proline & 130 & 115 \\
\hline Serine & 34 & 33 \\
\hline Threonine & 16 & 28 \\
\hline Tyrosine & 3 & 5 \\
\hline Tryptophan & 0 & 0 \\
\hline Valine & 20 & 24 \\
\hline Total & $\mathbf{1 0 0 0}$ & $\mathbf{1 0 0 0}$ \\
\hline Imino acids & 225 & 188 \\
\hline
\end{tabular}

${ }^{*}$ Imino acids include proline and hydroxyproline.
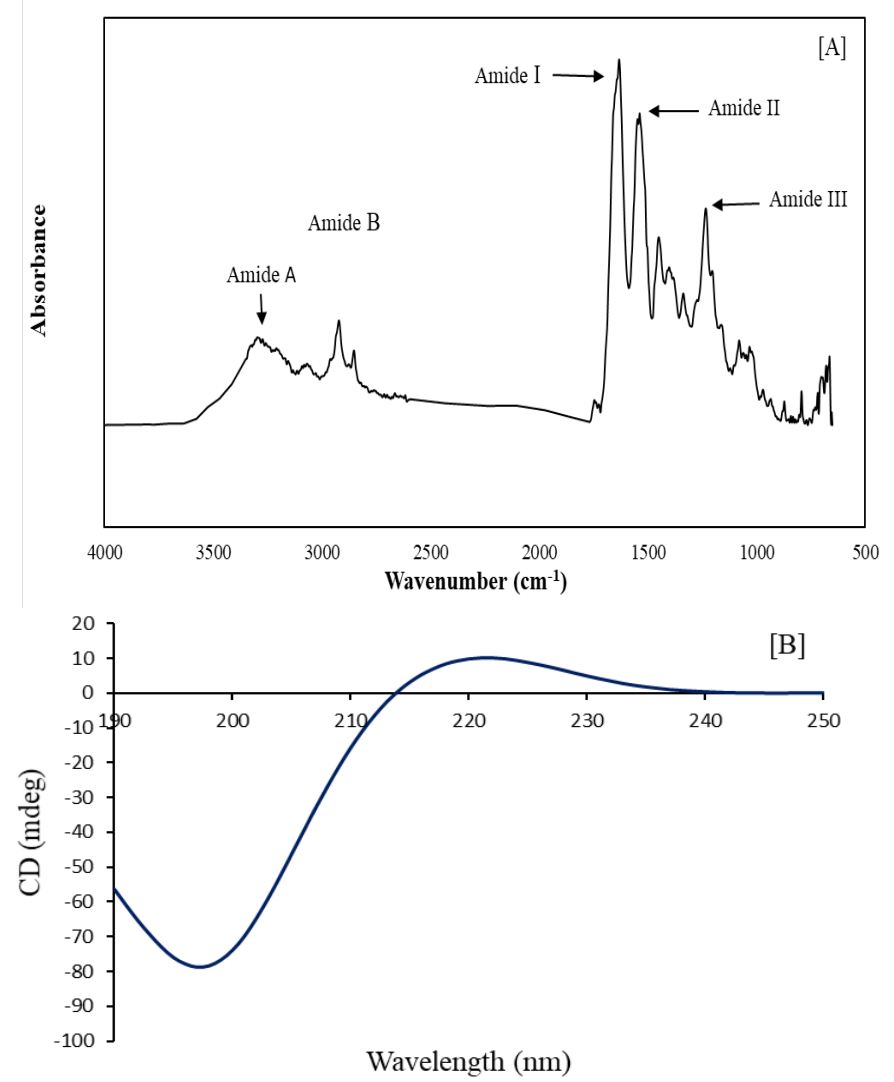

Figure 3. Fourier transform infrared (FTIR) [A] and circular dichroism (CD) [B] spectra of ASC from the skin of snakeskin gourami. 


\subsection{Thermal stability of ASC}

The $\mathrm{T}_{\max }$ and $\Delta \mathrm{H}$ of ASC estimated from DSC thermogram were $33.43{ }^{\circ} \mathrm{C}$ and $1.15 \mathrm{~J} / \mathrm{g}$, respectively. Thermal stability of collagen was governed by pyrrolidine rings of proline and hydroxyproline and partially by hydrogen bonding through the hydroxyl group of hydroxyproline (Benjakul et al., 2010). However, the $T_{\max }$ value might also be determined by the conformation and amino acid sequence of collagen (Ali et al., 2018). $\mathrm{T}_{\max }$ values of ASC from snakeskin gourami were higher than those previously reported for collagens from several fish species. $\mathrm{T}_{\max }$ of ASC from the skin of snakeskin gourami was in accordance with those of cold-water fish such as cod $\left(15^{\circ} \mathrm{C}\right)$, Alaska pollack $\left(16.8{ }^{\circ} \mathrm{C}\right)$, Japanese seabass $\left(30^{\circ} \mathrm{C}\right)$, skip jack tuna $(29.7$ ${ }^{\circ} \mathrm{C}$ ) and ayu $\left(29.7{ }^{\circ} \mathrm{C}\right.$ ) (Sinthusamran et al., 2013; Yu et al., 2014) or collagen from the skin of tropical fish such as brownstripe red snapper $\left(31.5^{\circ} \mathrm{C}\right)$, bigeye snapper $\left(30.4{ }^{\circ} \mathrm{C}\right)$, black drum fish $\left(34.2^{\circ} \mathrm{C}\right)$, sheepshead seabream $(34$ ${ }^{\circ} \mathrm{C}$ ) (Jongjareonrak et al., 2005; Kittiphattanabawon et al., 2010; Ogawa et al., 2003). The differences in Tmax amongst collagens from different species were correlated with different imino acid contents, body temperature and environmental temperature (Duan et al., 2009; Kittiphattanabawon et al., 2005).

\subsection{Secondary structure of ASC}

The FTIR spectrum of ASC from the skin of snakeskin gourami exhibited characteristic peaks of amide A and B, as well as amide I, II, III (Figure 3A). The major peaks found in ASC were similar to those of collagens isolated from other fish species (Kaewdang et al., 2014; Kittiphattanabawon et al., 2010; Li et al., 2020). The amide A was found at a wave numbers of $3288 \mathrm{~cm}^{-1}$ and associated with $\mathrm{N}-\mathrm{H}$ stretching vibration, which occurs in the wave number range of $3400-3440 \mathrm{~cm}^{-1}$ (Purna Sai and Babu, 2001). Also, when the NH group of a peptide is involved in a hydrogen bond, the position is shifted to a lower frequency (Ali et al., 2018). The amide B was found at a wave number of $3067 \mathrm{~cm}^{-1}$, associated with the asymmetrical stretch of $\mathrm{CH}_{2}$ (Muyonga et al., 2004). The wave number of amide I, amide II and amide III bands are directly associated with the configuration of collagen. The amide I band with the characteristic strong absorbance in the range of $1600-1700 \mathrm{~cm}^{-1}$ was mainly related to the $\mathrm{C}=\mathrm{O}$ stretching vibration along the polypeptide backbone, and it could be a sensitive marker of peptide's secondary structure (Sinthusamran et al., 2013). The amide I band of ASC was found at the wavenumber of $1631 \mathrm{~cm}^{-1}$. The amide II band of ASC was situated at a wave number of 1546 $\mathrm{cm}^{-1}$, while the amide III band of ASC was located at wave number $1232 \mathrm{~cm}^{-1}$. The amide II and amide III bands represent $\mathrm{N}-\mathrm{H}$ bending vibration and $\mathrm{C}-\mathrm{H}$ stretching, respectively (Naderi Gharagheshlagh et al., 2019). As a consequence, ASC was still conserved in its secondary structure. The CD spectrum of ASC scanned in the range of $190-250 \mathrm{~nm}$ is shown in Figure $3 \mathrm{~B}$. The $\mathrm{CD}$ curves showed a rotatory maximum at $222 \mathrm{~nm}$ and minimum at $197 \mathrm{~nm}$, and a consistent crossover point at about 214 $\mathrm{nm}$, which is a typical characteristic of triple helical conformation of collagen (Ikoma et al., 2003). CD spectra represents backbone configuration of protein through absorption regions of peptide linkage (Ogawa et al., 2004). ASC exhibited distinct positive and negative absorbance for a native collagen, while denatured collagen has a more distorted spectrum, reflected by the disappearance of a positive peak at $221 \mathrm{~nm}$ as well as negative peak shifts to lower absorption than $198 \mathrm{~nm}$ as reported by Ali et al. (2017). The results confirmed that ASC had high structural integrity without denaturation.

\subsection{Solubility of ASC}

The effect of $\mathrm{NaCl}$ on collagen solubility is shown in Figure 4A. The high solubility of ASC in $0.5 \mathrm{M}$ acetic acid was maintained in the presence of $\mathrm{NaCl}$ up to $1-2 \%$. Solubility of ASC decreased gradually when the $\mathrm{NaCl}$ 
concentration exceeded $2 \%$ and was also reduced when the $\mathrm{NaCl}$ concentration was $6 \%$. This result is in accordance with the reports on the solubility of collagens from the skins of yellowfin tuna, dusky spinefoot, sea chub, eagle ray, red stingray, yantai stingray, brownstripe red snapper, bigeye snapper and striped catfish in acetic acid solution generally decreased with an increase in $\mathrm{NaCl}$ concentration (Jongjareonrak et al., 2005; Kittiphattanabawon et al., 2005). This effect could be due to the "salting out" of collagen, which occurred at relatively high concentration of $\mathrm{NaCl}$ (Singh et al., 2011). According to Matmaroh et al. (2011), at low concentrations of $\mathrm{NaCl}$, salt ions are bound weakly to the charged groups on the protein surfaces without affecting the hydration shell on those domains. These results support the use of collagen from fish scales and skin as an alternative source for use in food, pharmaceutical and nutraceutical industries.

The zeta potential is a key indicator of the stability of colloidal dispersions. ASC from snakeskin gourami at different $\mathrm{pH}$ levels is shown in Figure 4B. At $\mathrm{pH} 2-6$, collagen sample were positively charged, and negatively charged between a $\mathrm{pH}$ of 7-10 with the net charge of zero at $\mathrm{pH}$ of 6.23 . When $\mathrm{pH}$ values were above or below pI values of the proteins, the repulsion between the protein chains increased resulting in a high net charge and the solubility of protein molecules. When the net charge of a protein was zero, hydrophobichydrophobic interactions increased, resulting in protein precipitation and aggregation (Ali et al., 2018). Collagens extracted from various fish have been shown to exhibit different $\mathrm{pI}$ values. For example, the pI value of collagen from striped catfish skin was 4.27 (Singh et al., 2011), collagen from spotted golden goatfish scales had a pI of 4.96 (Matmaroh et al., 2011), and the pI of bamboo shark skin collagen was 6.12 (Kittiphattanabawon et al., 2010). The slight differences in pI between collagens from various fish species might be caused by the slight difference in their amino acid sequences and distribution of amino acid residues.

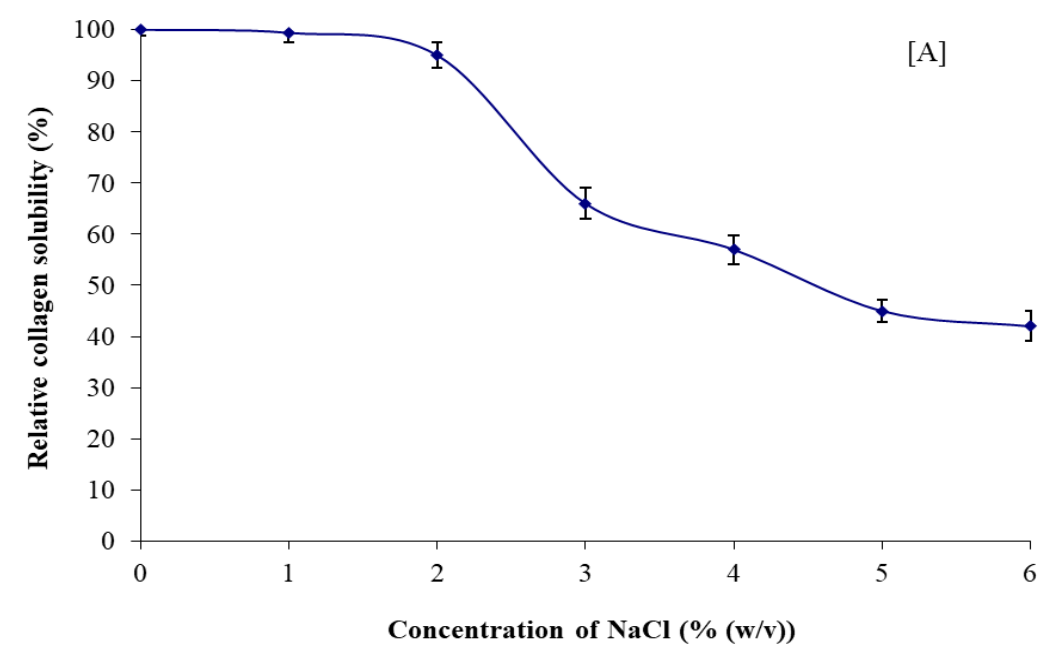




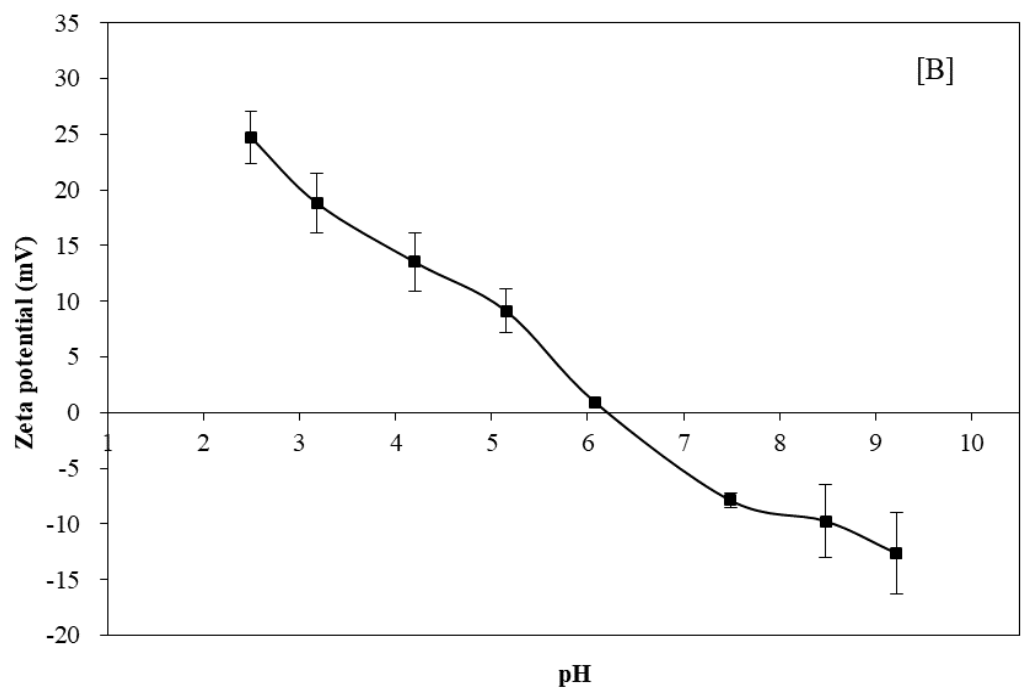

Figure 4. Solubility at different $\mathrm{NaCl}$ concentrations [A] and Zeta potential at different $\mathrm{pHs}[\mathrm{B}]$ of ASC from the skin of snakeskin gourami.

\section{Conclusions}

Collagen from the skin of snakeskin gourami was simply extracted by using acetic acid. Based on SDS-PAGE and amino acid composition, ASC was characterized to be type I collagen. The structural integrity of ASC was well preserved as determined by FTIR and circular dichroism. The solubility of ASC was depended on $\mathrm{pH}$ and $\mathrm{NaCl}$ concentration. Since collagen has a wide range of commercial uses, and based on obtained results, ASC from skin of snakeskin gourami can be a promising means of alternative source to produce collagen mainly from the fish processing industries.

\section{References}

Ali, A.M.M., Benjakul, S., Kishimura, H. (2017). Molecular characteristics of acid and pepsin soluble collagens from the scales of golden carp (Probarbus jullieni). Emirates Journal of Food and Agriculture, 29(6), 450-457.

Ali, A.M.M., Kishimura, H., Benjakul, S. (2018). Extraction efficiency and characteristics of acid and pepsin soluble collagens from the skin of golden carp (Probarbus Jullieni) as affected by ultrasonication. Process Biochemistry, 66, 237-244.
Benjakul, S., Thiansilakul, Y., Visessanguan, W., Roytrakul, S., Kishimura, H., Prodpran, T., Meesane, J. (2010). Extraction and characterisation of pepsinsolubilised collagens from the skin of bigeye snapper (Priacanthus tayenus and Priacanthus macracanthus). Journal of the Science of Food and Agriculture, 90(1), 132-138.

Duan, R., Zhang, J., Du, X., Yao, X., Konno, K. (2009). Properties of collagen from skin, scale and bone of carp (Cyprinus carpio). Food Chemistry, 112(3), 702-706.

Edwards, H.G.M., Farwell, D.W., Holder, J.M., Lawson, E.E. (1997). Fourier-transform Raman spectroscopy of ivory: II. Spectroscopic analysis and assignments. Journal of Molecular Structure, 435(1), 49-58.

Foegeding, E., Lanier, T.C., Hultin, H.O. (1996). Characteristics of edible muscle tissue In: 3 (Ed.), Food Chemistry. Marcel Dekker, New York, pp. 879-942.

Froese, R.a.P., Daniel, eds., (2014). Trichopodus pectoralis in FishBase., Accessed February 2017.

Huang, Y.R., Shiau, C.Y., Chen, H.H., Huang, B.C. (2011). Isolation and characterization of acid and pepsin-solubilized collagens 
from the skin of balloon fish (Diodon holocanthus). Food Hydrocolloids, 25(6), 1507-1513.

Ikoma, T., Kobayashi, H., Tanaka, J., Walsh, D., Mann, S. (2003). Physical properties of type I collagen extracted from fish scales of Pagrus major and Oreochromis niloticas. International Journal of Biological Macromolecules, 32(3), 199204.

Jongjareonrak, A., Benjakul, S., Visessanguan, W., Tanaka, M. (2005). Isolation and characterization of collagen from bigeye snapper (Priacanthus macracanthus) skin. Journal of the Science of Food and Agriculture, 85(7), 1203-1210.

Kaewdang, O., Benjakul, S., Kaewmanee, T., Kishimura, H. (2014). Characteristics of collagens from the swim bladders of yellowfin tuna (Thunnus albacares). Food Chemistry, 155, 264-270.

Kittiphattanabawon, P., Benjakul, S., Visessanguan, W., Kishimura, H., Shahidi, F. (2010). Isolation and characterisation of collagen from the skin of brownbanded bamboo shark (Chiloscyllium punctatum). Food Chemistry, 119(4), 1519-1526.

Kittiphattanabawon, P., Benjakul, S., Visessanguan, W., Nagai, T., Tanaka, M. (2005). Characterisation of acid-soluble collagen from skin and bone of bigeye snapper (Priacanthus tayenus). Food Chemistry, 89(3), 363-372.

Kittiphattanabawon, P., Sriket, C., Kishimura, H., Benjakul, S. (2019). Characteristics of acid and pepsin solubilized collagens from Nile tilapia (Oreochromis niloticus) scale. Emirates Journal of Food and Agriculture, 31(2), 95-01.

Laemmli, U.K. (1970). Cleavage of Structural Proteins during the assembly of the head of bacteriophage T4. Nature, 227, 680.

Li, P.H., Lu, W.C., Chan, Y.J., Ko, W.C., Jung, C.C., Le Huynh, D.T., Ji, Y.X. (2020). Extraction and characterization of collagen from sea cucumber (Holothuria cinerascens) and its potential application in moisturizing cosmetics. Aquaculture, 515, 734590 .

Lowry, O.H., Rosebrough, N.J., Farr, A.L., Randall, R.J. (1951). Protein measurement with the Folin phenol reagent. The Journal of Biological Chemistry, 193(1), 265-275.

Lui, H., Li, D., Guo, S. (2007). Studies on collagen from the skin of channel catfish (Ictalurus punctaus). Food Chemistry, 101(2), 621-625.

Matmaroh, K., Benjakul, S., Prodpran, T., Encarnacion, A.B., Kishimura, H. (2011). Characteristics of acid soluble collagen and pepsin soluble collagen from scale of spotted golden goatfish (Parupeneus heptacanthus). Food Chemistry, 129(3), 1179-1186.

Montero, P., Borderias, J., Turnay, J., Leyzarbe, M.A. (1990). Characterization of hake (Merluccius merluccius L.) and trout (Salmo irideus Gibb) collagen. Journal of Agricultural and Food Chemistry, 38(3), 604-609.

Muyonga, J.H., Cole, C.G.B., Duodu, K.G. (2004). Characterisation of acid soluble collagen from skins of young and adult Nile perch (Lates niloticus). Food Chemistry, 85(1), 81-89.

Naderi Gharagheshlagh, S., Fatemi, M.J., Jamili, S., Sharifi, A.M., Nourani, M.R. (2019). Isolation and characterization of acid-soluble collagen from the skin of Rutilus Frisii Kutum (Kamensky) of the Caspian Sea. Iranian Journal of Fisheries Sciences, doi:10.22092/ijfs.2019.118957.

Nalinanon, S., Benjakul, S., Kishimura, H., Osako, K. (2011). Type I collagen from the skin of ornate threadfin bream (Nemipterus hexodon): Characteristics and effect of pepsin hydrolysis. Food Chemistry, 125(2), 500-507.

Nalinanon, S., Benjakul, S., Visessanguan, W., Kishimura, H. (2007). Use of pepsin for collagen extraction from the skin of bigeye snapper (Priacanthus tayenus). Food Chemistry, 104(2), 593-601. 
Ogawa, M., Moody, M.W., Portier, R.J., Bell, J., Schexnayder, M.A., Losso, J.N. (2003). Biochemical properties of black drum and sheepshead seabream skin collagen. Journal of Agricultural and Food Chemistry, 51(27), 8088-8092.

Ogawa, M., Portier, R.J., Moody, M.W., Bell, J., Schexnayder, M.A., Losso, J.N. (2004). Biochemical properties of bone and scale collagens isolated from the subtropical fish black drum (Pogonia cromis) and sheepshead seabream (Archosargus probatocephalus). Food Chemistry, 88(4), 495-501.

Pongsri, C.a.S., N. (2005). National Aquaculture Sector Overview. Thailand. National Aquaculture Sector Overview Fact Sheets., FAO Fisheries and Aquaculture Department http://www.fao.org/fishery/countrysector/n aso thailand/en (2005). Accessed 8 February 2017.

Purna Sai, K., Babu, M. (2001). Studies on Rana tigerina skin collagen. Comparative Biochemistry and Physiology Part B: Biochemistry and Molecular Biology, 128(1), 81-90.

Singh, P., Benjakul, S., Maqsood, S., Kishimura, H. (2011). Isolation and characterisation of collagen extracted from the skin of striped catfish (Pangasianodon hypophthalmus). Food Chemistry, 124(1), 97-105.

Sinthusamran, S., Benjakul, S., Kishimura, H. (2013). Comparative study on molecular characteristics of acid soluble collagens from skin and swim bladder of seabass (Lates calcarifer). Food Chemistry, 138(4), 2435-2441.

Wang, L., An, X., Xin, Z., Zhao, L., Hu, Q. (2007). Isolation and characterization of collagen from the skin of deep-sea redfish (Sebastes mentella). Journal of Food Science, 72(8), E450-E455.

Yu, D., Chi, C.-F., Wang, B., Ding, G.-F., Li, Z.-R. (2014). Characterization of acid-and pepsin-soluble collagens from spines and skulls of skipjack tuna (Katsuwonus pelamis). Chinese Journal of Natural Medicines, 12(9), 712-720.

Zeng, S., Yin, J., Yang, S., Zhang, C., Yang, P., $\mathrm{Wu}, \quad$ W. (2012). Structure and characteristics of acid and pepsinsolubilized collagens from the skin of cobia (Rachycentron canadum). Food Chemistry, 135(3), 1975-1984.

\section{Acknowledgments}

This work was financially supported by King Mongkut's Institute of Technology Ladkrabang and the Thailand Toray Science Foundation (TTSF). The authors would also like to thank Professor Dr. Anthony Keith Thompson, Visiting Professor under the Academic Melting Pot program at the Faculty of Food Industry, King Mongkut's Institute of Technology Ladkrabang, for invaluable suggestion and correction. 